\title{
Tsafon
}

Revue d'études juives du Nord

$81 \mid 2021$

Des synagogues à travers les âges Lieux de prières, lieux d'études et autres fonctions

\section{Savy Pierre Histoire des Juifs. Un voyage en 80 dates de l'Antiquité à nos jours}

\section{Danielle Delmaire}

\section{(2) OpenEdition}

\section{Journals}

Édition électronique

URL : https://journals.openedition.org/tsafon/4008

DOI : $10.4000 /$ tsafon.4008

ISSN : 2609-6420

Éditeur

Association Jean-Marie Delmaire

Édition imprimée

Date de publication : 1 juillet 2021

Pagination : 159-160

ISSN : $1149-6630$

Référence électronique

Danielle Delmaire, "Savy Pierre Histoire des Juifs. Un voyage en 80 dates de l'Antiquité à nos jours », Tsafon [En ligne], 81 | 2021, mis en ligne le 01 juillet 2021, consulté le 15 septembre 2021. URL : http:// journals.openedition.org/tsafon/4008; DOI : https://doi.org/10.4000/tsafon.4008

Ce document a été généré automatiquement le 15 septembre 2021

Tsafon. Revues d'études juives du Nord 


\title{
Savy Pierre Histoire des Juifs. Un voyage en 80 dates de l'Antiquité à nos jours
}

\author{
Danielle Delmaire
}

\section{RÉFÉRENCE}

Savy Pierre (sous la direction de), Histoire des Juifs. Un voyage en 80 dates de l'Antiquité à nos jours, Paris, Presses universitaires de France, sept. 2020, 586 p., $29 €$.

1 En collaboration avec Katell Berthelot (directrice de recherche au CNRS et spécialiste du judaïsme de l'époque hellénistique et romaine) et Audrey Kichelewski (maîtresse de conférences en histoire contemporaine à l'université de Strasbourg et membre junior de l'Institut universitaire de France), Pierre Savy (directeur des études pour le Moyen Âge à l'École française de Rome) publie un ensemble de 80 textes sur l'histoire des Juifs dans le monde et couvrant pas moins de 32 siècles (de 1207 av notre ère avec la stèle de Mérenptah à la prise d'otages de l'Hyper Cacher en 2015) : une gageure! Les choix ont dû susciter bien des discussions et nécessairement le lecteur pourra toujours déplorer un, voire plusieurs oublis.

2 Lors d'une visio conférence pour présenter l'ouvrage, P. Savy se défendait de vouloir écrire une histoire lacrymale et déclarait retenir aussi des périodes et des événements heureux de ce passé juif. Il assumait aussi des absences comme Masssada, la Nuit de Cristal, plus regrettable Qumran ou le procès de Nuremberg ou encore Ben Yehouda. En revanche, le lecteur aura plaisir à découvrir des faits moins connus comme la date de 212 lorsque les Juifs deviennent des citoyens romains, ou des personnages restés trop longtemps dans l'ombre comme la publication des poèmes de Debora Corcos Ascarelli, une première pour une poétesse, et la nomination de la première femme rabbin en 1935. 
3 Très souvent une date est le prétexte pour développer une histoire plus longue. Par exemple, l'article de Perrine Simon-Nahum qui présente la fondation de la Wissenschaft des Judentums prolonge l'étude jusqu'à la fin du XIX ${ }^{\mathrm{e}}$ siècle avec la Science du Judaïsme en France. De même Cyril Grange informe sur la dynastie des Rothschild à partir de la date du 29 septembre 1822, jour où « l'empereur d'Autriche François I ${ }^{\text {er }}$ élève au rang de baron les cinq fils de Mayer Amschel Rothschild». L'affaire de Simon de Trente, exposée par Pierre Savy, permet d'écrire une brève histoire des meurtres rituels.

4 Les notices sont confiées à des spécialistes du sujet traité comme Christian Ingrao sur la conférence de Wannsee ou Catherine Nicault sur la déclaration Balfour, ou encore Thomas Römer sur le début de l'empire perse pour la date de 539 avant notre ère et Dominique Bourel pour un texte sur Moses Mandelssohn. Les trois directeurs de l'ouvrage ont réussi à rassembler 70 auteurs pour ces 80 dates.

5 On l'aura compris, l'œuvre est à consulter à la manière d'une encyclopédie, bien que réduite. Il faut saluer les outils de fin de pages : les trois index très utiles, des noms, des lieux et des matières. Et chaque article est suivi d'une brève bibliographie.

6 Une question se pose : qu'est-ce qui différencie cet ouvrage de l'Histoire universelle des Juifs dirigée par Élie Barnavi (1992 et 2002) ? Celui de Barnavi se présente davantage comme une sorte d'atlas avec une iconographie bien plus abondante pour chaque thème traité sur une double page. Ici les auteurs développent plus longuement un sujet, environ cinq à six pages, les différentes notices sont de longueur à peu près uniforme, et les illustrations comme les cartes sont rares.

7 Malgré ses faiblesses inhérentes au choix des directeurs, cette histoire de Juifs en 80 dates doit figurer dans les bibliothèques des curieux de cette histoire, des instituts et des départements d'université spécialisés dans les études juives. 